Cahiers $d u$ MONDE RUSSE

\section{Cahiers du monde russe}

Russie - Empire russe - Union soviétique et États indépendants

45/3-4 | 2004

Varia

\title{
Marina Vilenovna Babič, Gosudarstvennye učreždenija XVIII veka
}

Anna Lecerf

\section{(2) OpenEdition}

Journals

Édition électronique

URL : https://journals.openedition.org/monderusse/4176

DOI : 10.4000/monderusse.4176

ISSN : 1777-5388

Éditeur

Éditions de l'EHESS

Édition imprimée

Date de publication : 1 juillet 2004

Pagination : 630-632

ISBN : 2-7132-2009-2

ISSN : $1252-6576$

Référence électronique

Anna Lecerf, "Marina Vilenovna Babič, Gosudarstvennye učreždenija xvIII veka », Cahiers du monde russe [En ligne], 45/3-4 | 2004, mis en ligne le 16 juin 2009, consulté le 03 septembre 2022. URL : http://journals.openedition.org/monderusse/4176; DOI : https://doi.org/10.4000/monderusse.4176

Ce document a été généré automatiquement le 3 septembre 2022.

Tous droits réservés 


\title{
Marina Vilenovna Babič, Gosudarstvennye učreždenija XVIII veka
}

\author{
Anna Lecerf
}

\section{RÉFÉRENCE}

Marina Vilenovna BABIČ, Gosudarstvennye učreždenija xvIII veka. Komissii

petrovskogo vremeni (Les institutions d'État au XVIII siècle. Les commissions de l'époque de Pierre $\mathrm{I}^{\mathrm{er}}$ ). Moscou, « Rossijskaja političeskaja enciklopedija » (ROSSPEN), 2003, $480 \mathrm{p}$.

Le livre de Marina Vilenovna Babič ${ }^{1}$ est une contribution importante à la connaissance de l'histoire administrative russe de l'Ancien Régime, domaine qui a connu relativement peu de progrès entre le début du xxe siècle, quand les derniers historiens-juristes de la génération prérévolutionnaire quittèrent la scène scientifique, et les années 1990 où cette problématique a enfin trouvé un regain d'intérêt chez les modernistes russes.

Cette monographie est la première à traiter d'un bloc l'ensemble des « commissions » du règne pétrovien connues à ce jour. Les commissions sont des institutions aux attributions mixtes, administratives/judiciaires/policières et aux caractéristiques tellement variées que, strictement parlant, on ne leur trouve qu'un seul trait commun permettant de les considérer comme un type d'institution unique: toutes ces organisations furent en effet "temporaires", dans le sens où, au moment de leur création, on n'envisageait pas leur maintien au-delà d'un laps de temps nécessaire pour remplir une tâche ponctuelle et concrète (contrôle fiscal, recensement de la population et détermination de l'assiette de l'impôt, codification de la législation, délimitation des frontières et règlement des conflits frontaliers, instruction criminelle, organisation des cérémonies de couronnement, etc.). La position instable des commissions dans le 
système administratif (ainsi que l'extrême fragmentation de leurs archives) en font un objet historique difficile à analyser et qui a largement échappé à l'attention des historiens, alors que le rôle joué par ces institutions dans le gouvernement du pays, comme le montre clairement $\mathrm{M}$. V. Babič, fut crucial et que leur action s'avéra souvent indispensable pour le fonctionnement des institutions centrales "permanentes» (le Sénat et le système des collèges). L'auteur note avec perspicacité que l'étude de ces institutions fugitives, instaurées de manière impromptue et démantelées sans cérémonie, ouvre un accès plus direct à la réalité administrative de l'époque que l'observation des façades lisses des institutions " permanentes ", bâties suivant des plans idéologiquement chargés et rarement respectés en pratique.

L'ouvrage est composé de trois parties. La première, proprement monographique, commence par une description chronologique des premières commissions du règne pétrovien. Mais, très vite, les commissions devenant trop nombreuses, l'auteur adopte une démarche systématique. Passant en revue, l'un après l'autre, les différents groupes des commissions dont elle donne des descriptions factuelles denses et riches de renseignements nouveaux, M.V.Babič cherche à dégager trois ensembles de traits caractéristiques des commissions : ceux qui permettent de les considérer comme un type d'institution particulier et unique ; ceux qui prouvent que, malgré leur spécificité, les commissions forment une partie intégrante du système collégial; ceux enfin qui distinguent les commissions entre elles et permettent d'établir leur typologie interne. Cette méthode tire son inspiration de l'école juridique du xixe siècle. Elle est efficace quand il s'agit de ratisser les méandres des archives administratives de l'Ancien Régime, mais son potentiel cognitif proprement historique est faible : ce procédé vise surtout à établir une classification rigoureuse des institutions, alors que les contemporains, selon ce qu'on en connaît, ne s'en souciaient guère. De façon un peu paradoxale, M. V. Babič se limite strictement à cette approche tout en reconnaissant ses insuffisances. Ainsi s'obstine-t-elle à nier l'existence de liens d'hérédité typologique entre les commissions et les prikazy (secrétariats) du xvire siècle et à souligner l'appartenance des commissions au système collégial, bien qu'elle constate elle-même - avec une lucidité rare - la valeur toute relative et entièrement théorique (voire idéologique) de l'opposition entre les prikazy et les collèges, qui représente aujourd'hui encore un des lieux communs de l'historiographie.

Le propos de l'auteur acquiert une dimension quasi dramatique quand au terme d'une longue et patiente analyse, fondée uniquement sur les critères formels, elle conclut à l'impossibilité de répondre à la question centrale de sa recherche, c'est-à-dire d'expliquer, à partir de tels critères, l'essor des commissions sous le règne de Pierre Ier, et quand elle se demande s'il ne faut pas chercher les raisons de cet essor plutôt dans le domaine des mentalités. De la même façon, après s'être attachée - dans un esprit fonctionnaliste habituel qui conditionne l'existence entière des institutions administratives par leurs fonctions (gérer, juger, etc.) - à une étude minutieuse des différentes tâches remplies par les commissions, M. V. Babič constate "l'indifférence des cercles gouvernementaux au "bon" ou "mauvais" déroulement des "affaires" » confiées aux commissions et arrive à une hypothèse suggestive selon laquelle le déploiement des institutions temporaires refléterait moins les préoccupations d'efficacité dans notre sens du terme que le souci de manifester l'omniprésence du pouvoir. 
On regrettera le style extrêmement lourd de cette partie et la présence de nombreuses fautes grammaticales qui rendent difficile sa lecture jusqu'à obscurcir totalement certains passages.

Les deux dernières parties du livre représentent des instruments de recherche et de référence précieux pour les historiens de l'administration russe. La deuxième (p. 164-414) contient une sorte de dictionnaire systématisé des commissions pétroviennes. Chacun des 139 articles renseigne six rubriques : 1. le(s) nom(s) de la commission, les dates de son existence et ses institutions de subordination; 2. des précisions concernant les divergences éventuelles (fréquentes) entre les attributions et les dates de fonctionnement officielles et factuelles; 3. le personnel et, éventuellement, les traits spécifiques de fonctionnement ; 4 . les raisons de la création de la commission donnée, ses objectifs et les résultats de son activité; 5 . les cotes d'archives de la documentation laissée par la commission (dans la majorité des cas, localisée et identifiée par l'auteur); 6. bibliographie.

La troisième partie du livre (p. 415-467) représente un dictionnaire prosopographique du personnel dirigeant des commissions (plus de 280 entrées). Il fournit de nombreuses informations introuvables dans les encyclopédies et dictionnaires classiques, aussi bien sur les activités importantes, mais souvent ignorées, des figures historiques célèbres que sur les biographies "professionnelles» des personnages plus modestes injustement oubliés.

L'ouvrage de M.V.Babič est une véritable mine d'informations très variées sur les institutions pétroviennes qu'on peut glaner au fil des pages, plume à la main. Mais l'admiration qu'on éprouve devant la connaissance empirique profonde de l'auteur et sa maîtrise archivistique impressionnante ne fait que renforcer le sentiment de l'inadéquation de l'approche formaliste dans l'étude des institutions administratives, qu'il serait temps de rénover entièrement.

\section{NOTES}

1. M. V. Babič est l'auteur de plusieurs articles et ouvrages, dont Gosudarstvennye učreždenija Rossii XVIII veka. Spravočnoe posobie (Les institutions d'État en Russie au XVIII ${ }^{e}$ siècle. Bibliographie critique), Moscou, Editorial URSS, 1999, 144 p., qui contient une bibliographie complète des publications en langue russe concernant l'histoire des institutions politiques et administratives aux niveaux central et local. 